\title{
COVID-19: challenges and opportunities
}

\section{Adam J Singer, Bettina C Fries}

Departments of Emergency Medicine and Medicine, Renaissance School of Medicine at Stony Brook University, Stony Brook, NY, USA

Introduction of antibiotics in the first half of the 20th century led some to believe that the era of infectious diseases was coming to an end. However, the emergence of new and deadly diseases such as human immunodeficiency virus, Ebola, and now coronavirus disease 2019 (COVID-19) has taught us that infectious diseases will remain a challenge for a long time to come. While the current pandemic has placed considerable strain on healthcare systems worldwide ${ }^{1,2}$ much has been learned in the short period since the disease emerged in late 2019.

A paper in this Journal by Choi et al. ${ }^{3}$ demonstrates how the technologically advanced Korean healthcare system has responded to the COVID-19 pandemic by creation of novel drive through and walk through facilities that allow rapid and safe viral testing helping to identify and isolate patients with the disease as well a track contacts to help reduce the pandemic spread. Another paper in this issue by Rola et al. ${ }^{4}$ highlights how much the traditional approach to hypoxemic respiratory failure has changed with COVID-19. While invasive mechanical ventilation has generally been used early in refractory hypoxemia, we now recognize that many patients present with profound hypoxemia (even with oxygen levels previously thought to be incompatible with life) with little distress. This phenotype has been called the L phenotype or the so-called "happy hypoxemic" patient..$^{5}$ In these cases, use of oxygen by high flow nasal cannula or noninvasive ventilation together with proning may help avoid invasive mechanical ventilation or delay the need for, and duration of, subsequent invasive ventilation thus helping to preserve scarce and vital resources.

It is truly amazing how much we have learned about the virus, its pathogenesis, and its management in such a short period of time. COVID-19 usually leads to hospitalization because the SARS-CoV-2 (severe acute respiratory syndrome-coronavirus 2) virus infects pneumocytes resulting in acute lung injury and acute respiratory distress syndrome leading to profound hypoxemia. Also, in some hosts, the viral infection elicits an exaggerated immune response which is characterized by a cytokine storm. ${ }^{6}$ Rather than being protective this immune response promotes further damage including renal failure and it also fails to clear the virus. In addition, high levels of D-dimer have been observed and COVID-19 autopsies demonstrate pathophysiological changes in the microvasculature and alveoli that further undermine respiratory functions and can even lead to deep vein thrombosis, pulmonary emboli, and strokes.?

As we continuously learn more about COVID-19, our strategies how to treat patients continue to evolve. In addition to optimizing supportive care, drugs that target the lifecycle of the virus as well as drugs that inhibit the immune response have been investigated. Promising in vitro and in vivo results as well as some therapeutic experiences from treatment of severe acute respiratory syndrome and Middle East respiratory syndrome identified lead candidates. Organizing and implementing clinical trials in the midst of the pandemic surge can be very challenging and physi-
Received: 25 May 2020

Revised: 3 June 2020

Accepted: 3 June 2020

Correspondence to: Adam J Singer Departments of Emergency Medicine and Medicine, Renaissance School of Medicine at Stony Brook University, HSC L4-080 8350 SUNY, Stony Brook, NY 11794-8300, USA

E-mail: Adam.Singer@ stonybrookmedicine.edu ORCID https://orcid.org/0000-0003-4694-6152

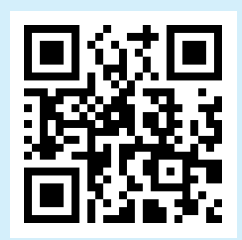

How to cite this article: Singer AJ, Fries BC. COVID-19: challenges and opportunities. Clin Exp Emerg Med 2020;7(3):141-143. https://doi.org/10.15441/ ceem. 20.054

This is an Open Access article distributed under the terms of the Creative Commons Attribution Non-Commercial License (https:// creativecommons.org/licenses/by-nc/4.0/). 
cians in the setting of despair tend to prefer compassionate use protocols over randomized trials, in part because families of infected patients struggle with the concept of being treated with a placebo drug. The need to maintain an evidence-based approach has become increasingly evident when it was noted that positive results of non-randomized trials could not be reproduced in other studies. For instance, early studies indicated potential benefit of hydroxychloroquine. ${ }^{8,9}$ In contrast, larger studies with hydroxychloroquine did not result in a significantly higher probability of good outcome, and instead, demonstrated that adverse events were higher in recipients compared to non-recipients. ${ }^{10}$ Also, despite favorable preliminary study results, a randomized trial of lopinavir-ritonavir failed to show benefit, ${ }_{1}^{11}$ although when used in combination with interferon and ribavirin, lopinavir-ritonavir therapy might be beneficial. More successful results have been achieved with remdesivir, which is a novel nucleotide analog prodrug. A recent randomized trial of over 1,000 hospitalized COVID-19 patients demonstrated that remdesivir was superior to placebo in shortening time to recovery. ${ }^{12}$ As a result, remdesivir achieved rapid emergent Food and Drug Administration approval and is now recommended for most patients with COVID-19 disease and significant hypoxemia. Newer trials now seek to combine this antiviral with other immunomodulating drugs such as tumor necrosis factor, and CCR5 antagonists or antiviral antibodies. Several drugs targeting interleukin- 6 are also being actively investigated and preliminary data from non-randomized trials indicate that these drugs may be beneficial. The role of convalescent plasma is also being studied in over 5000 patients with severe or life-threatening COVID-19 disease. ${ }^{13}$ Lastly, a recent study demonstrated improved outcomes in COVID-19 patients randomized to dexamethasone, especially in those with sever disease. ${ }^{14}$

Most important for emergency providers are the upcoming trials examining the protective efficacy of several vaccine candidates, which are rapidly advancing. These vaccines will protect front line personnel and hopefully allow us to build adequate herd immunity in our community so that we can prevent COVID-19 altogether or at least, limit the number of patients that transition to critical COVID-19 disease.

While the COVID-19 pandemic has been very challenging, it also has opened up a whole host of research opportunities that have the potential to greatly enhance our basic biologic understanding and treatment of many diseases beyond just COVID-19. Just like previous wars have led to great advances in medicine, we must take advantage of the current pandemic as well as the widespread public support and funding surrounding COVID-19 to help us continue to learn even more about how to take better care of current and future patients.

\section{CONFLICT OF INTEREST}

No potential conflict of interest relevant to this article was reported.

\section{REFERENCES}

1. Singer AJ, Morley EJ, Henry MC. Staying ahead of the wave. N Engl J Med 2020;382:e44.

2. Richardson $S$, Hirsch JS, Narasimhan $M$, et al. Presenting characteristics, comorbidities, and outcomes among 5700 patients hospitalized with COVID-19 in the New York city area. JAMA 2020;323:2052-9.

3. Choi S, Han C, Lee J, Kim SI, Kim IB. Innovative screening tests for COVID-19 in South Korea. Clin Exp Emerg Med 2020 Apr 16. https://doi.org/10.15441/ceem.20.032.

4. Rola P, Farkas J, Spiegel $R$, et al. Rethinking the early intubation paradigm of COVID-19: time to change gears? Clin Exp Emerg Med 2020 Jun 10. https://doi.org/10.15441/ceem.20.043.

5. Gattinoni L, Chiumello D, Caironi P, et al. COVID-19 pneumonia: different respiratory treatments for different phenotypes? Intensive Care Med 2020 April 14. https://doi.org/10.1007/ s00134-020-06033-2.

6. Azkur AK, Akdis M, Azkur D, et al. Immune response to SARSCoV-2 and mechanisms of immunopathological changes in COVID-19. Allergy 2020 May 12. https://doi.org/10.1111/all. 14364.

7. Hanley B, Lucas SB, Youd E, Swift B, Osborn M. Autopsy in suspected COVID-19 cases. J Clin Pathol 2020;73:239-42.

8. Chen Z, Hu J, Zhang Z, et al. Efficacy of hydroxychloroquine in patients with COVID-19: results of a randomized trial. medRxiv [Priprint]. [posted 2020 April 10; cited 2020 Jun 1]. Available from: https://doi.org/10.1101/2020.03.22.20040758.

9. Gautret P, Lagier JC, Parola P, et al. Clinical and microbiological effect of a combination of hydroxychloroquine and azithromycin in 80 COVID-19 patients with at least a six-day follow up: a pilot observational study. Travel Med Infect Dis 2020;34: 101663.

10. Mehra MR, Desai SS, Ruschitzka F, Patel AN. Hydroxychloroquine or chloroquine with or without a macrolide for treatment of COVID-19: a multinational registry analysis. Lancet 2020 May 22. https://doi.org/10.1016/S0140-6736(20)31180-6.

11. Cao B, Wang $Y$, Wen $D$, et al. A Trial of Lopinavir-Ritonavir in adults hospitalized with severe Covid-19. N Engl J Med 2020; 382:1787-99.

12. Beigel $J H$, Tomashek $K M$, Dodd $L E$, et al. Remdesivir for the treatment of Covid-19: preliminary report. N Engl J Med 2020 
May 22. https://doi.org/10.1056/NEJMoa2007764.

13. Joyner M, Wright RS, Fairweather $D$, et al. Early safety indicators of COVID-19 convalescent plasma in 5,000 patients. medRxiv [Preprint]. [posted 2020 May 14; cited 2020 Jun 1]. Avail- able from: https://doi.org/10.1101/2020.05.12.20099879.

14. https://www.ox.ac.uk/news/2020-06-16-low-cost-dexamethasone-reduces-death-one-third-hospitalized-patientssevere. Accessed June 17, 2020. 